\title{
ORNL CONTRIBUTION TO THE IAEA BENCHMARK PROBLEM ON FISSION REACTOR DECOMMISSIONING
}

\author{
B. L. Broadhead and R. L. Childs \\ Computational Physics and Engineering Division \\ Oak Ridge National Laboratory* \\ P.O. Box 2008 \\ Oak Ridge, Tennessee USA 37831-6370
}

To be Presented at

ANS 1996 Radiation Protection and Shielding Division Topical Meeting Advancements and Applications in Radiation Protection and Shielding

April 21-25, 1996

Cape Cod, Massachusetts

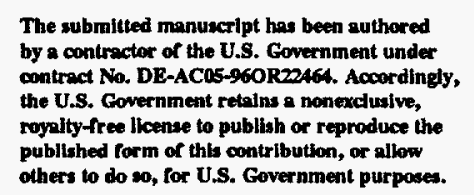

*Managed by Lockheed Martin Energy Research Corp. for the U.S. Department of Energy under contract DE-AC05-96OR22464. 


\title{
ORNL CONTRIBUTION TO THE IAEA BENCHMARK PROBLEM ON FISSION REACTOR DECOMMISSIONING
}

\author{
B. L. Broadhead and R. L. Childs \\ Oak Ridge National Laboratory* \\ P.O. Box 2008 \\ Oak Ridge, Tennessee USA 37831-6370 \\ (423) $576-4476$
}

\begin{abstract}
Recently the IAEA selected a benchmark problem for calculation of radioactivity inventories and dose estimates necessary for fission reactor decommissioning. Several researchers were invited to participate in the solution of this benchmark problem set. The contribution from ORNL is presented herein.
\end{abstract}

\section{INTRODUCTION}

In the United States and worldwide, a number of nuclear power and research reactors are currently approaching shutdown status. In the United States the four alternatives for decommissioning are: (1) no immediate action, (2) immediate dismantlement, (3) safe storage followed by deferred dismantlement, and (4) entombment.

Documentation of the selected decommissioning mode along with background information and the rationale used in mode selection must be included in the decommissioning process. Key components in this selection are the quantity, time variation, and spatial distribution of activation products in and around the reactor vessel, which are important both for worker safety (radiation exposure) and planning activities (total Curie inventories and waste classification category). The time variation aspect of this inventory information is key in the selection of which decommissioning mode to choose (most important activation products have half-lives under ten years).

An evaluation of the current status of nuclear data and methods for quantifying activation products for fission reactor decommissioning needs was undertaken by an advisory group to the International Atomic Energy Agency (IAEA). The advisory group" listed a total of four recommendations "in order to improve the nuclear data and the methods of their use for calculation of radioactivity inventories and dose estimates

\footnotetext{
*Managed by Lockheed Martin Energy Research Corp. for the U.S. Department of Energy under contract DEAC05-960R22464.
} 
necessary for fission reactor decommissioning." One of these recommendations was to establish a benchmark problem set to allow benchmark tests by various countries to establish calculational accuracies for activation products in and around a decommissioned fission reactor. The IAEA selected a benchmark problem corresponding to the decommissioned Japanese Power Demonstration Reactor (JPDR) ${ }^{2}$ This paper describes the Oak Ridge National Laboratory (ORNL) contribution to this benchmark problem solution.

\section{APPROACH}

The problem of in-vessel and ex-vessel activation in fission reactor materials can be analyzed using a number of different approaches. They typically involve the use of a point-depletion code to quantify the time-dependent material concentrations while using differing approximations to account for the neutron flux and cross-section variations spatially. This work utilizes a number of utility tools available within the SCALE system ${ }^{3}$ to study many of these various approximations.

In the most general case, both the neutron fluxes and cross sections are time-dependent and spatialdependent. To estimate the effect of variation of the cross sections with time, an existing SCALE module, SAS2H, was used to obtain time-dependent cross sections spatially averaged over the JPDR biological shield. These resulting average activities can then be scaled based on the neutron flux profile to obtain estimates of the activity profiles in the biological shield.

A second approach to solving the reactor material activation problem was utilization of several SCALE utility modules (MALOCS, NITAWL, WINE, and COUPLE) to effectively allow the creation of specific cross-section libraries for arbitrary spatial points, each of which can then be analyzed using the point-depletion code ORIGEN-S. This approach allows the study of the importance of cross-section spatial variations, as well as one-dimensional (1-D) versus two-dimensional (2-D) neutron flux representations. Using this approach, estimates of the activity profiles in the biological shield were made using both 1-D and 2-D neutron flux solutions for the JPDR pressure vessel and biological shield.

The initial cross-section library utilized in this study was the SCALE 27-neutron-group set based on ENDF/B-IV data. The cross-section variation studies and initial activation studies were based on this library. However, a series of 1-D solutions performed with both the 27-group and the VITAMIN-B6 library in 199-neutron groups indicated significant differences. As a result, a 67-neutron-group library was generated for final results. This 67 -group library was collapsed from the 199-group library with a spectrum corresponding to the JPDR pressure vessel. The 67 -group structure is essentially the BUGLE-93 ${ }^{4}$ 47group structure with 20 thermal groups added.

\section{RESULTS}

The effect of variations in the cross sections with time was estimated using an existing SCALE module, SAS2H, to obtain time-dependent cross sections spatially averaged over the JPDR biological shield. These cross sections were generated as energy-averaged one-group cross sections for the major activity materials by reactor cycle number. The one-group cross sections in all cases are essentially constant with time, thus time-dependent cross-section libraries are not necessary in further studies. 
Spatial variations in the energy-averaged one-group cross sections were estimated using a procedure similar to the above calculations. The results are shown in Fig. 1 for the primary activity materials in the biological shield. The cross sections are given as a function of distance into the biological shield. It is apparent that an equilibrium spectrum is established rapidly at a distance of 20 to $30 \mathrm{~cm}$ into the shield. Thus it appears that an approach of obtaining the average activity in the shield, followed by a scaling based on the flux profile, should produce reasonable activation results. Indeed this approach was attempted with results that compared favorably with the more sophisticated procedures.

After the exploratory studies described above were completed, a procedure was developed to effectively allow cross-section libraries to be generated for any arbitrary location in the reactor facility where flux information is available. The procedure can obtain the flux information based on either 1- or 2-D solutions, generate the appropriate libraries, and execute the point-depletion code for a particular location. A schematic of the 2-D version of this procedure is shown in Fig. 2. This procedure was applied to the JPDR pressure vessel and biological shields using both the 1- and 2-D models included in the benchmark description.

The 1-D results based on the SCALE 27-group library are given in Figs. 3 and 4 for the pressure vessel and biological shields. These results correspond to near the reactor midplane and are compared with the set of measurements nearest to the reactor axial centerline. The 1-D pressure vessel results are up to an order of magnitude smaller than the measurements but have trends similar to the Japanese predictions included in the benchmark description. The results in the biological shield show trends similar to those of the measurements; however, near the surface of the biological shield the predictions underestimate the measurements, while deep into the shield the predictions overestimate the measured activities.

Results from 2-D models generated with the SCALE 27-group library are given in Fig. 5 corresponding to the JPDR pressure vessel and Fig. 6 corresponding to the biological shield. The results in Fig. 6 show trends similar to the measurements as well as the 1-D predictions. While not obvious from comparison of the results in Figs. 3 and 5, the 2-D results are about a factor of 2 higher than the 1-D results. While the 2-D predictions match the measurements in the steel clad region near the reactor midplane, the 2-D calculations are up to a factor of 5 to 6 below the measurements elsewhere.

Two-dimensional results are shown in Figs. 5 and 6 for various activation materials near the midplane and for ${ }^{60} \mathrm{Co}$ activation at various axial levels in the JPDR biological shield, respectively. The 2-D results in both figures correspond well with those of the Japanese in that reasonably good agreement with measurements is seen near the front of the biological shield with overpredictions up to a factor of 5 to 10 deep into the shield.

As a result of the differences seen between fine- and broad-group results, a new cross-section library, consisting of 67-neutron groups was generated by collapsing the 199-group library using a JPDR pressure vessel spectrum. The use of this library is then included in the activation procedure as shown in Fig. 2. Prior to this final set of calculations, a slight revised model of the JPDR biological shield was included in the IAEA benchmark description. These revisions include addition of steel rebar information into the concrete biological shield. These final results included the revised concrete materials.

Although only the biological shield configuration was updated, calculations were performed for both the pressure vessel and biological shield to incorporate both the new biological shield specifications and the 
updated calculational procedure described above. The latest results are presented in Figs. 7 and 8 for the pressure vessel and biological shield, respectively. These results are based on 2-D discrete-ordinates calculations and are, in general, closer to the measurements than the previous results. The pressure vessel results in Fig. 7 match the measurements very closely at the front and near the back of the pressure vessel, while somewhat underpredicting the measurements in the middle of the vessel.

The biological shield predicted results in Fig. 8 are also closer to the measurements than the previous results, for the worst case approximately a factor of 4 to 5 higher as opposed to about a factor of 10 previously. Near the front of the biological shield the agreement between the calculations and measurements is quite good. As the distance into the shield increases, the predictions increase relative to the measurements. The improvement in the results while accounting for the rebar structure in the biological shield is encouraging; however, the agreement is still not very good near the outside of the shield.

\section{CONCLUSIONS}

Results shown in this work indicate reasonably good agreement between calculated and measured activities in the pressure vessel of the JPDR. However, in the biological shield the latest activation results tend to overpredict the measurements by up to a factor of 4 to 5 . The effects of inclusion of the rebar in the biological shield concrete were slight improvements in the activity predictions as compared to the measurements, but not sufficient to bring the results into good agreement. The source of the discrepancy in the biological is still not clearly understood. It is believed to be either the concrete/water densities or possibly a discrepant cross section in the concrete/water materials. A sensitivity analysis should allow for identification of possible primary contributors to the discrepancy, along with a combination with crosssection or density uncertainty information to estimate the uncertainties in the calculated activities in the

shield. It would also be beneficial to compare similar activation measurements and predictions for other reactor facilities to see if these trends are seen elsewhere.

\section{REFERENCES}

1. N.P. Kocherov, "Nuclear Data Requirements of Fission Reactor Decommissioning," Proceedings of the Advisory Group Meeting organized by the International Atomic Energy Agency, Vienna, September 7-11, 1992, INDC(NDS)-269, January 1993.

2. T. Sukegawa, N. Sasamoto, and K. Fujiki, Accuracy Verification for Calculation of Inventory In JPDR Due to Neutron Activation, INDC(JPN)-164, International Atomic Energy Agency, Vienna, March 1993.

3. SCALE: A Modular Code System for Performing Standardized Computer Analyses for Licensing Evaluation, NUREG/CR-0200, Rev. 4 (ORNL/NUREG/CSD-2/R4), Vols. 1-3, April 1993. Available from Radiation Shielding Information Center as CCC-545.

4. D. T. Ingersoll et al., Production and Testing of the VITAMIN-B6 Fine-Group and the BUGLE-93 Broad-Group Neutron/Photon Cross-Section Libraries Derived form ENDF/B-VI Nuclear Data, ORNL-6795, Lockheed Martin Energy Systems, Inc., Oak Ridge Natl. Lab., 1994. 


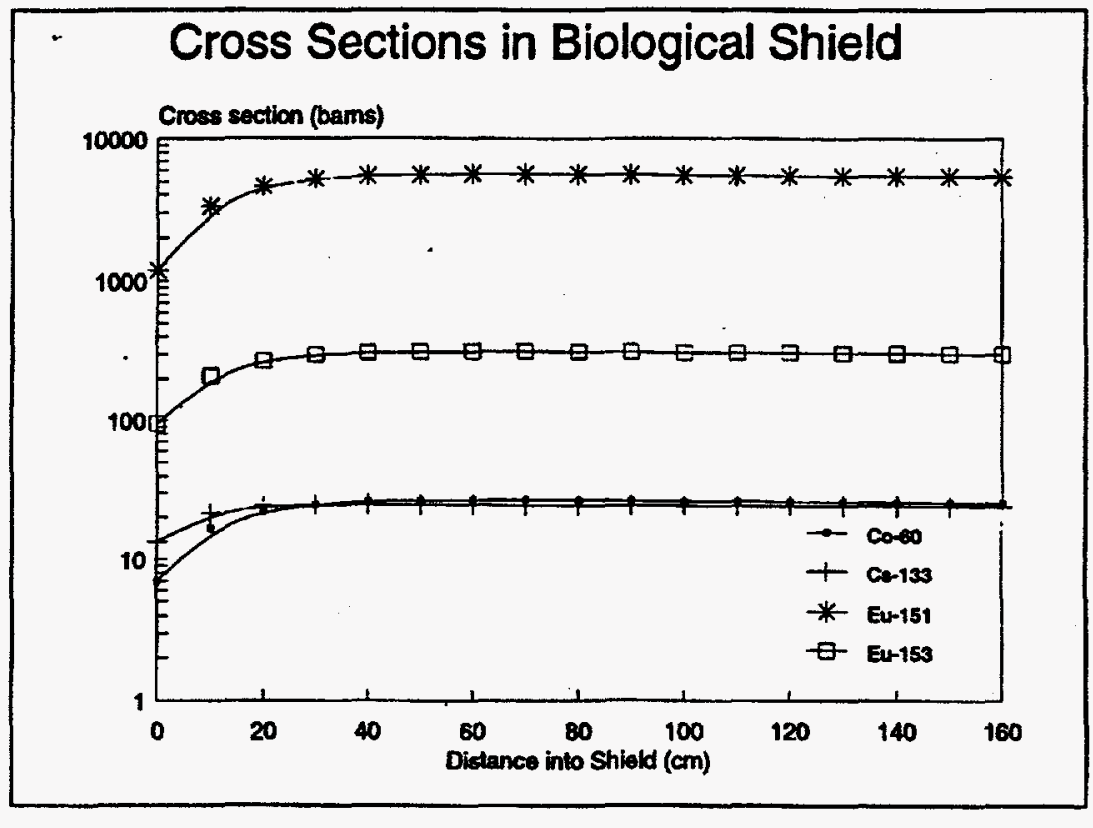

Fig. 1. Spatial variation in 1-group cross sections in the JPDR biological shield.

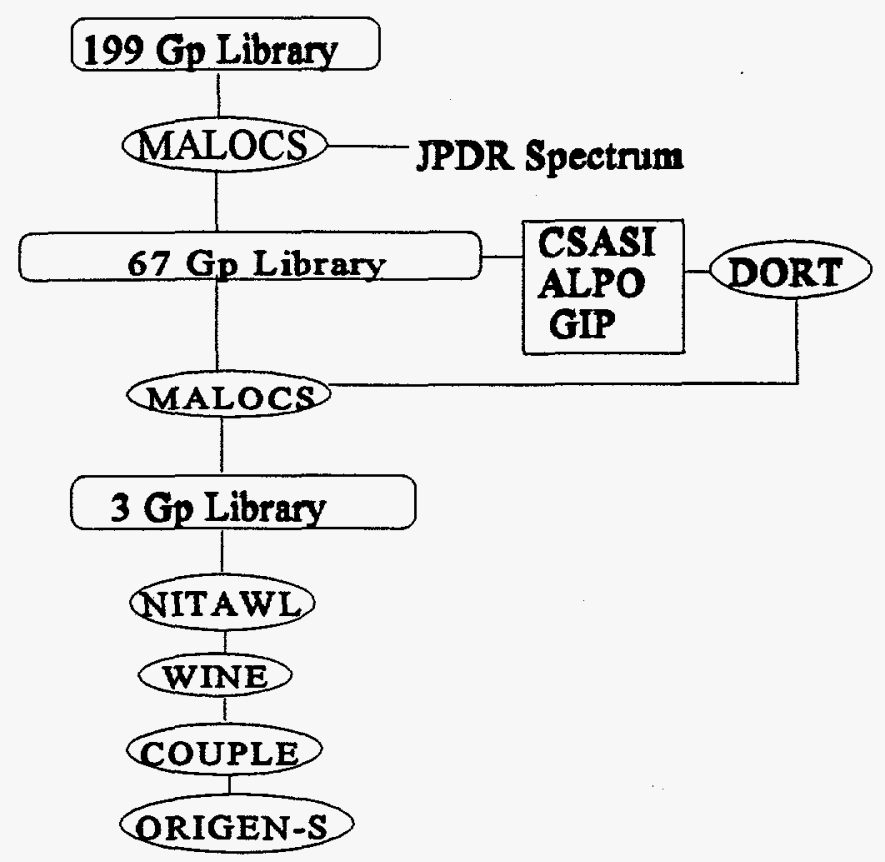

Fig. 2. JPDR activation calculational procedure. 


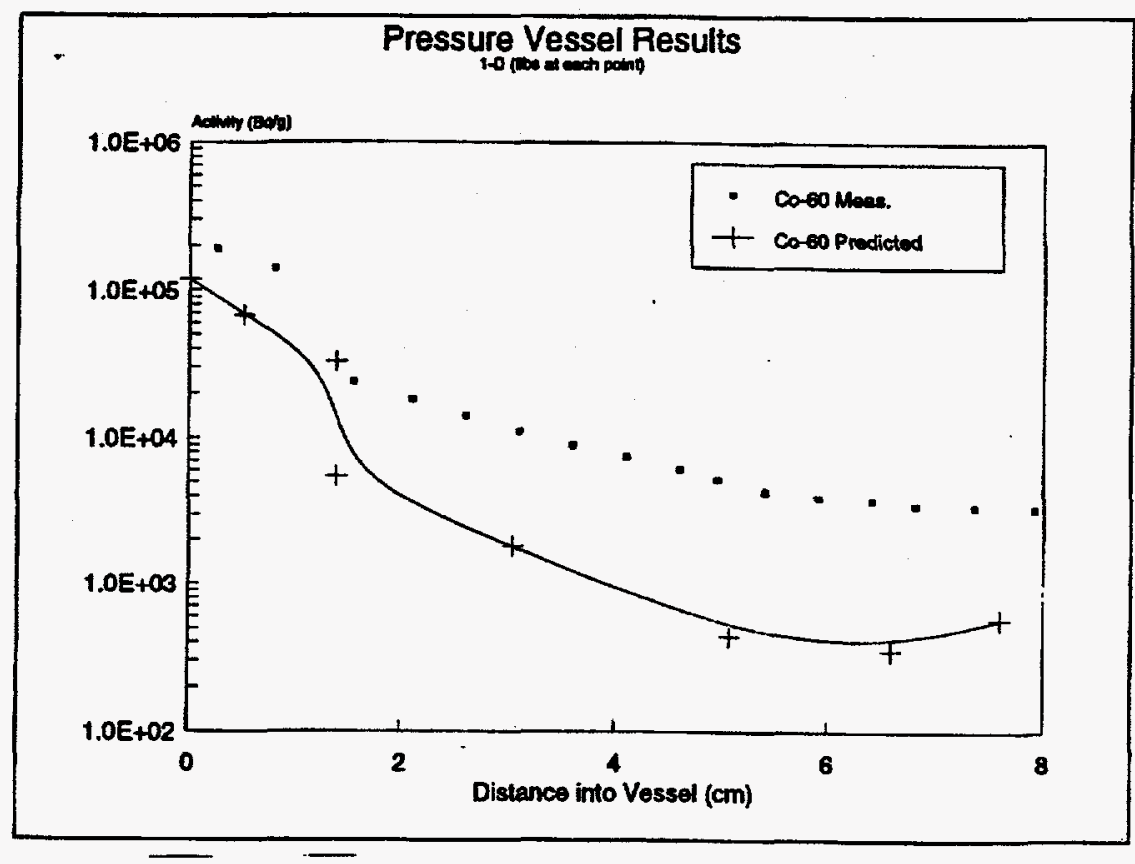

Fig. 3. One-dimensional ${ }^{60} \mathrm{Co}$ activation results in the JPDR pressure vessel.

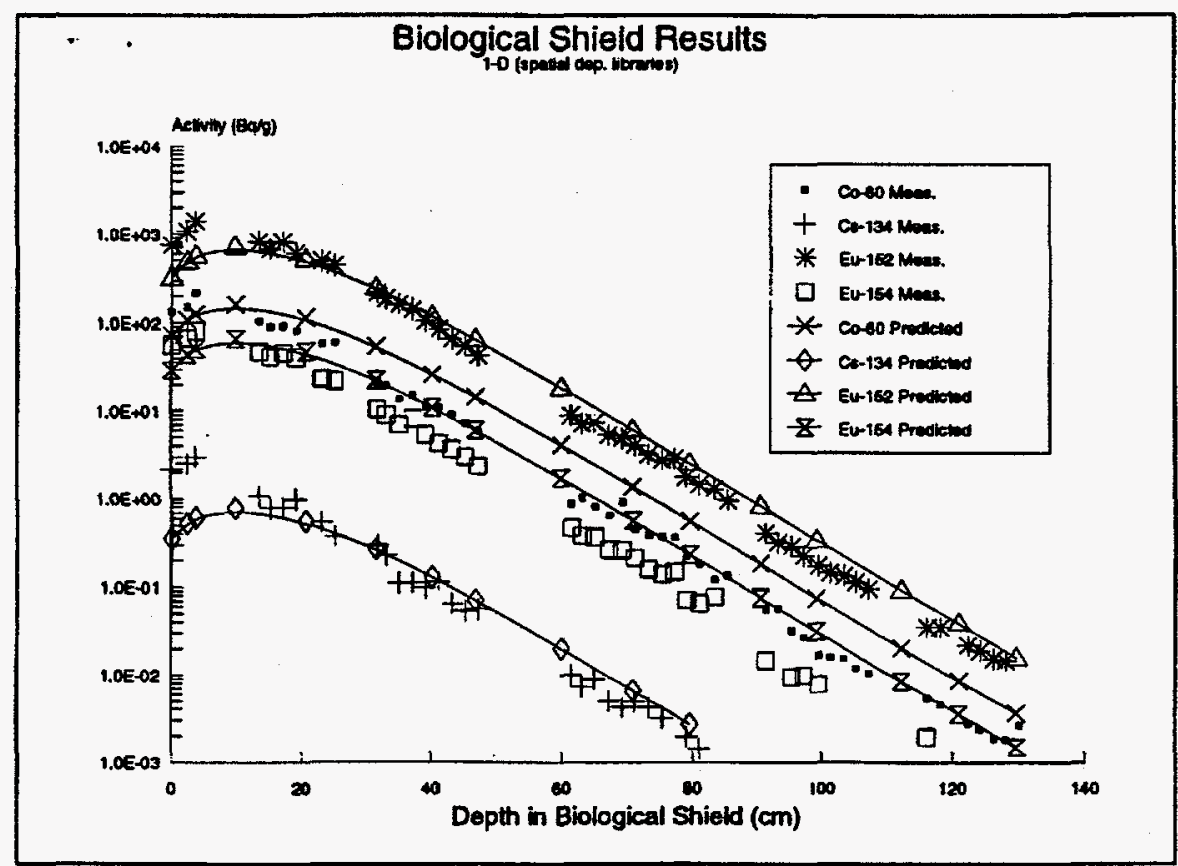

Fig. 4. One-dimensional activation results in the JPDR biological shield. 


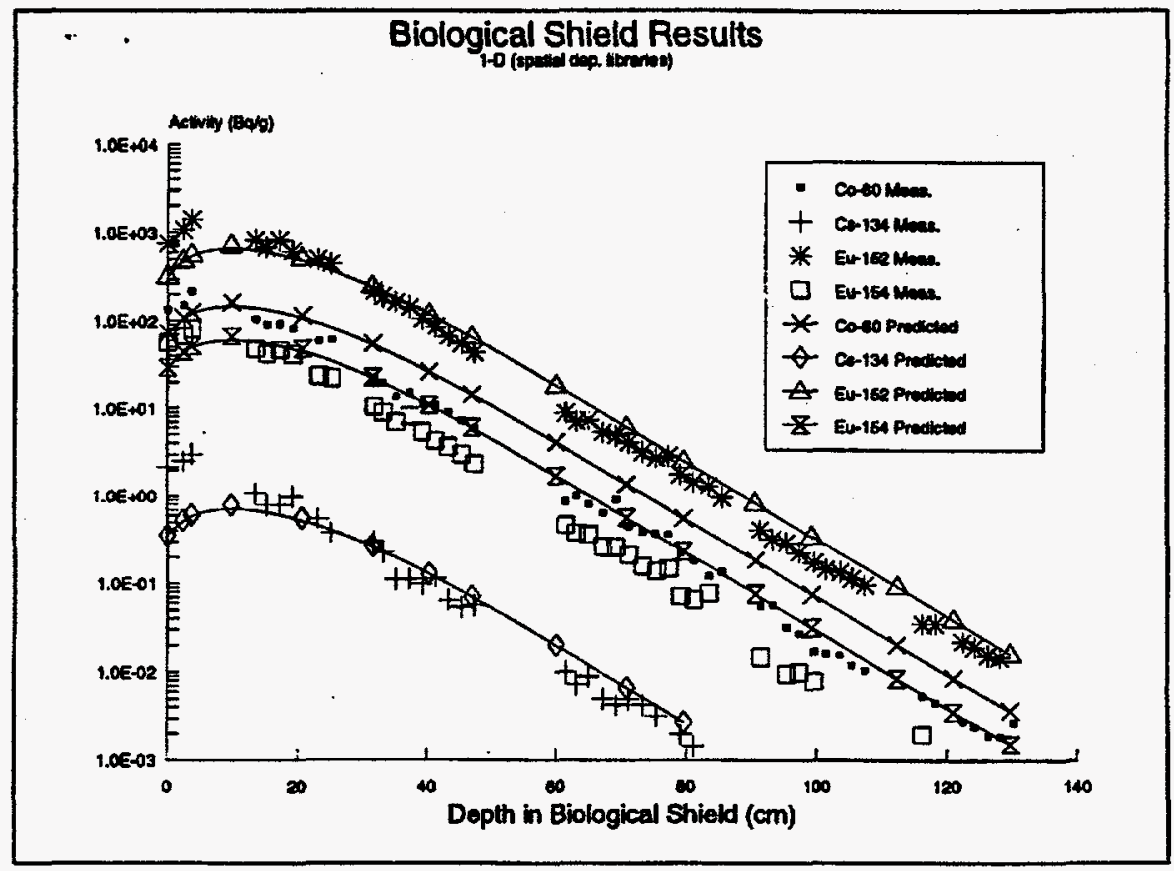

Fig. 5. Two-dimensional ${ }^{60} \mathrm{Co}$ activation predictions in the JPDR pressure vessel.

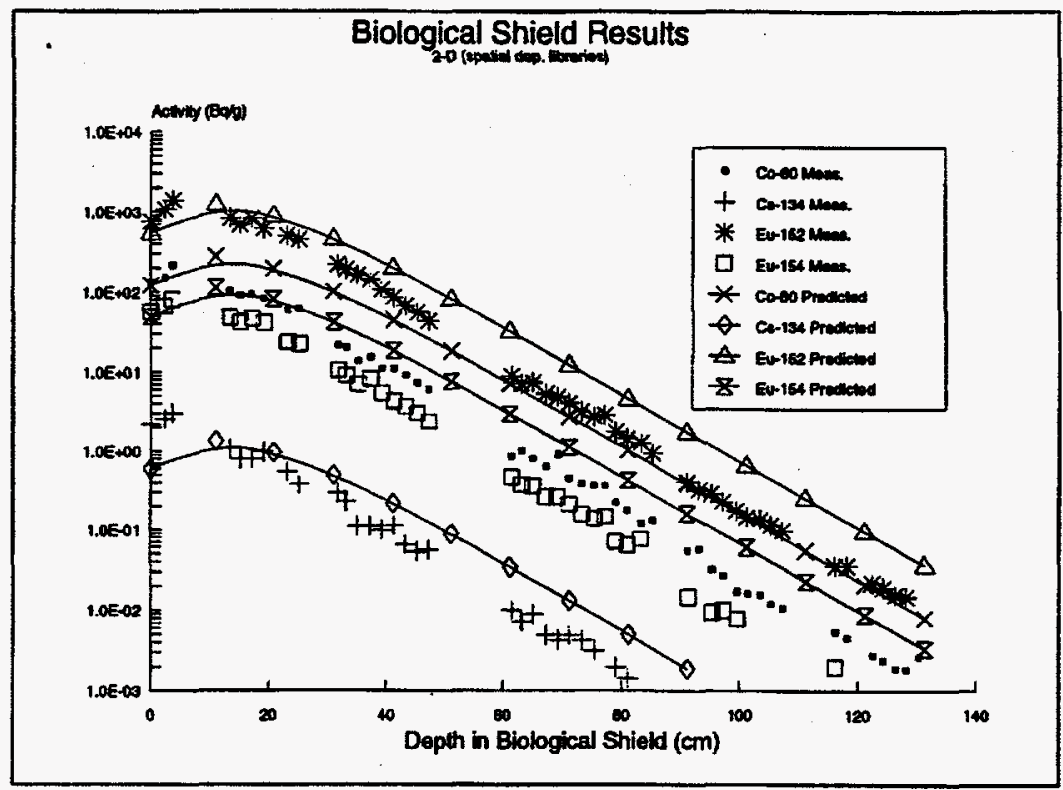

Fig. 6. Two-dimensional activation predictions in the JPDR biological shield. 


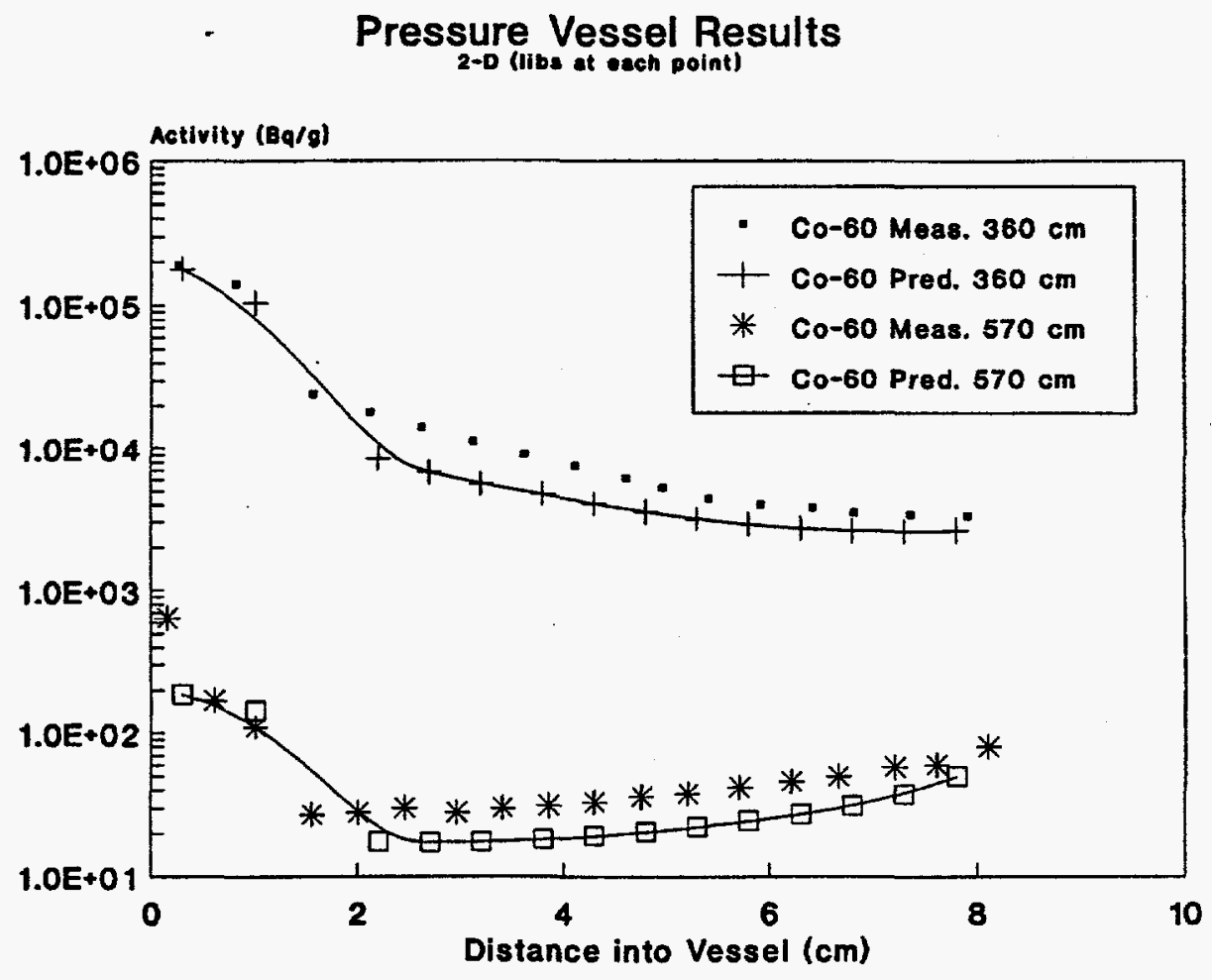

Fig. 7. Revised two-dimensional ${ }^{60} \mathrm{Co}$ activation predictions in the JPDR pressure vessel.

- Biological Shield Results

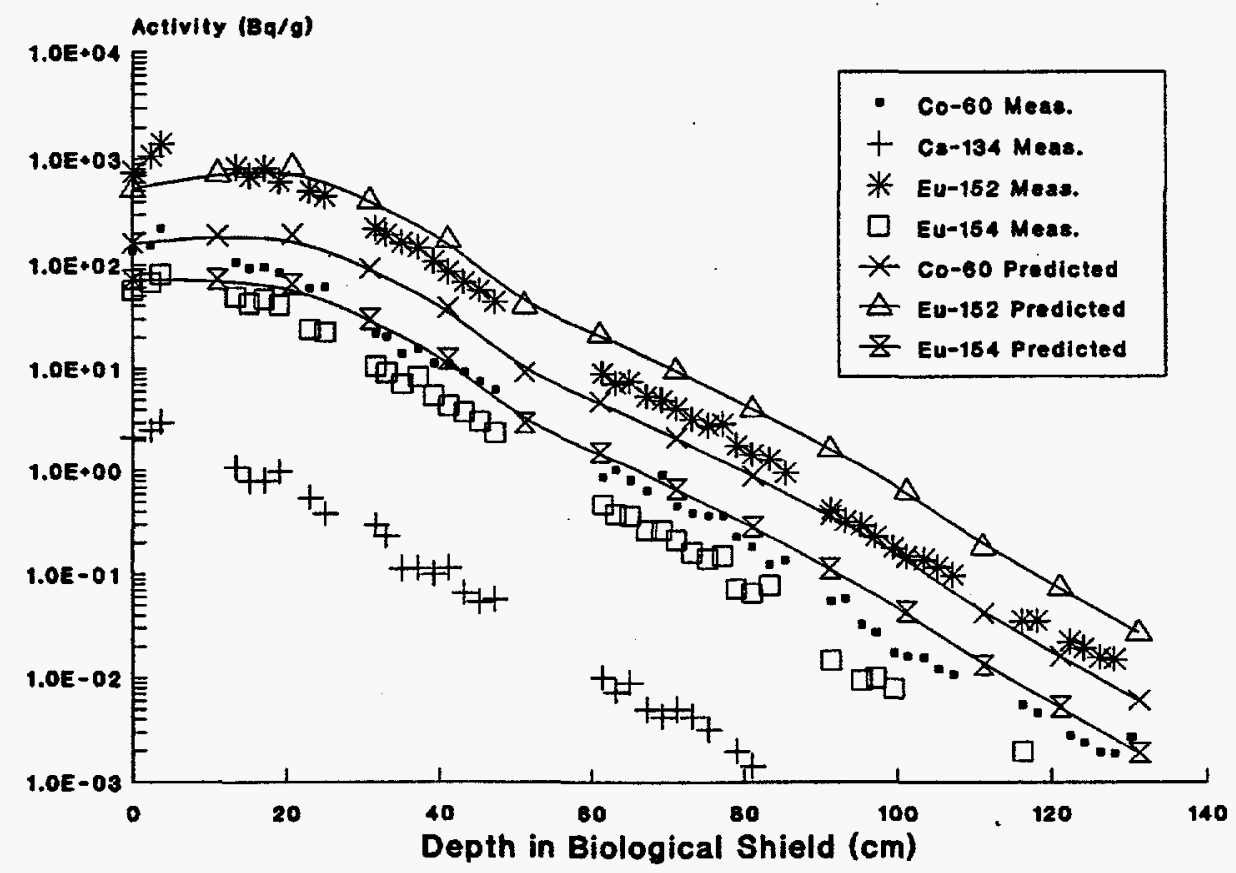

Fig. 8. Revised two-dimensional activation predictions in the JPDR biological shield. 


\section{DISCLAIMER}

This report was prepared as an account of work sponsored by an agency of the United States Government. Neither the United States. Government nor any agency thereof, nor any of their employees, makes any warranty, express or implied, or assumes any legal liability or responsibility for the accuracy, completeness, or usefulness of any information, apparatus, product, or process disclosed, or represents that its use would not infringe privately owned rights. Reference herein to any specific commercial product, process, or service by trade name, trademark, manufacturer, or otherwise does not necessarily constitute or imply its endorsement, recommendation, or favoring by the United States Government or any agency thereof. The views and opinions of authors expressed herein do not necessarily state or reflect those of the United States Government or any agency thereof. 